\title{
Serotonin syndrome presenting as surgical emergency: A report of two cases
}

\author{
Sanjay Prakash, Chaturbhuj Rathore
}
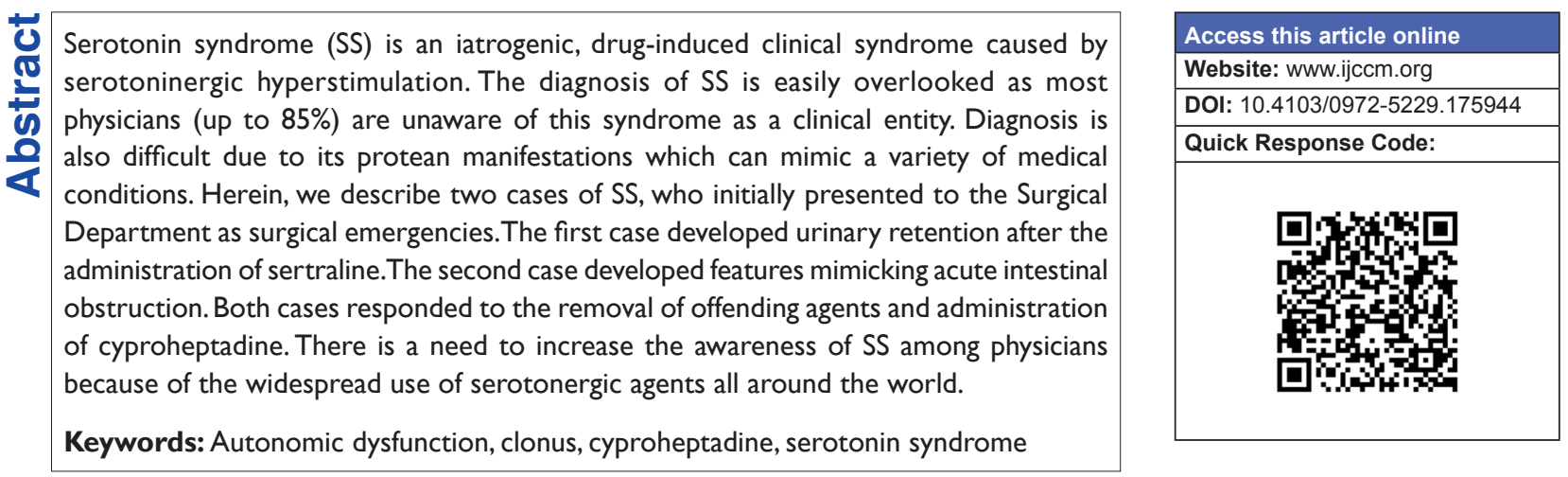

\section{Introduction}

Serotonin syndrome (SS) is a drug-induced clinical syndrome characterized by a clinical triad of neuromuscular hyperactivity, altered mental status, and autonomic hyperactivity. ${ }^{[1]}$ The clinical features range from mild nonspecific symptoms such as mild tremors to a life-threatening condition. The diagnosis of SS is easily overlooked as most physicians (up to 85\%) are not aware of this syndrome as a clinical entity. ${ }^{[1]}$ Diagnosis is also difficult due to its protean manifestations which can mimic a variety of medical conditions. ${ }^{[1,2]}$ Herein, we describe two patients with SS, who initially presented to surgical departments.

\section{Case Reports}

\section{Case 1}

A 62-year-old male attended Urology Department for voiding dysfunction which started as hesitancy for 2-3 days followed by acute retention of urine. Ultrasound

From:

Department of Neurology, Smt B. K. Shah Medical Institute and Research

Centre Medical College, Vadodara, Gujarat, India

\section{Correspondence:}

Dr. Sanjay Prakash, Department of Neurology, Smt B. K. Shah Medical Institute and Research Centre Medical College, Piperia, Waghodia,

Vadodara - 391 760, Gujarat, India.

E-mail: drprakashs@yahoo.co.in examination and urinalysis were normal. Cystometric study demonstrated decreased detrusor pressure at maximum urinary flow rate. Biochemical parameters were normal. After the initial catheterization, he was put on the intermittent catheterization and a neurology opinion was sought. Neurological examinations revealed coarse postural tremors, hypertonia, hyperreflexia, and ankle and knee clonus. The patient had been receiving sertraline ( $50 \mathrm{mg} /$ day) and clonazepam $(0.5 \mathrm{mg} /$ day) for the last 3-4 weeks for depression and insomnia.

The patient fulfilled the Hunter's criteria for SS. ${ }^{[1]}$ Fluoxetine was discontinued. Cyproheptadine was administered in an initial dose of $12 \mathrm{mg}$, followed by $2 \mathrm{mg}$ every 2 -h for $24 \mathrm{~h}$. Within $12 \mathrm{~h}$ of the administration of the first dose, the patient started to pass urine voluntarily. Other physical findings such as clonus, hyperreflexia, tremors, and hypertonia also disappeared in $48 \mathrm{~h}$. The dosing schedule of cyproheptadine was changed after

This is an open access article distributed under the terms of the Creative Commons Attribution-NonCommercial-ShareAlike 3.0 License, which allows others to remix, tweak, and build upon the work non-commercially, as long as the author is credited and the new creations are licensed under the identical terms.

For reprints contact: reprints@ @medknow.com

How to cite this article: Prakash S, Rathore C. Serotonin syndrome presenting as surgical emergency: A report of two cases. Indian J Crit Care Med 2016;20:120-2. 
$24 \mathrm{~h}$ to $8 \mathrm{mg}$ tds. Cyproheptadine was continued for another 7 days. In the next 6 months of follow-up, the patient has remained symptom-free.

\section{Case 2}

A 43-year-male had a long history of chronic back pain. Paroxetine (40 mg/day) and tramadol/acetaminophen combination (37.5/325 mg 3 times) were started for the recent exacerbation of back pain. Though backache improved, he developed abdominal pain, nausea and occasional vomiting on the $4^{\text {th }}$ day of the administration of the drugs. Oral ondansetron ( $8 \mathrm{mg} \mathrm{tds})$ was added for nausea and vomiting. His condition deteriorated with increasing abdominal pain, diffuse abdominal distension, and frequent vomiting. He was admitted in the surgery department with a possibility of acute intestinal obstruction. Abdominal examinations revealed tender, and distended abdomen with hyperactive bowel sound. Routine biochemical tests were normal. Plain abdominal X-ray showed dilated loops of small bowel. A diagnosis of intestinal obstruction was made. He was managed conservatively with nasogastric suctioning, intravenous fluids, and intravenous ondansetron. His condition further deteriorated, and he developed new symptoms such as agitation, irritability, restlessness, and tremors of both hands. At this point, a neurological consultation was sought.

Physical examinations revealed diaphoresis, mydriasis, postural-tremor, rigidity, hyperreflexia, and ankle and knee clonus. A diagnosis of SS was made. The patient had already stopped paroxetine and tramadol 2 days back. Ondansetron was discontinued. Cyproheptadine was administered at an initial dose of $12 \mathrm{mg}$, followed by $2 \mathrm{mg}$ every $2 \mathrm{~h}$ for $24 \mathrm{~h}$ through a nasogastric tube. Diaphoresis, agitation, and irritability disappeared completely in 24-h. Gastrointestinal features (abdominal pain, distention, and vomiting) also subsided in next $24 \mathrm{~h}$. After $48 \mathrm{~h}$, the dosing schedule of cyproheptadine was changed to $8 \mathrm{mg}$ tid and the patient was asked to continue for 7 days. In the next 2 months of follow-up, the patient was symptom-free.

\section{Discussion}

Both patients fulfilled the Hunter Serotonin Toxicity Criteria. Response to therapeutic doses of cyproheptadine further established the diagnosis of SS. Hunter criteria suggest that any person who had received serotonergic drug in the previous 5 weeks may develop SS. ${ }^{[1]}$ In Case 1, the patient developed bladder symptoms after 3-4 weeks of the administration of sertraline. In Case 2 , the patient was on two serotonergic agents, and he developed symptoms on the $4^{\text {th }}$ day. Unfortunately, he received another serotonergic drugs (ondansetron) and his condition deteriorated further.

Diagnosis of SS depends on the demonstration of a few specific physical signs (clonus, hyperreflexia, tremor, ocular clonus, hypertonia, etc.). Clonus is considered as the most important feature in establishing the diagnosis of the SS. ${ }^{[1]}$ Autonomic manifestations in SS include diaphoresis, tachycardia, hyperthermia, hypertension, vomiting, diarrhea, dilated pupil, and hyperactive bowel sound. ${ }^{[1,3]}$ Our both cases have prominent autonomic symptoms. In fact, symptoms related to autonomic features were the main reasons to seek initial medical consultation. In Case 1, symptoms started with voiding dysfunctions and, later on, other features were added. In Case 2, SS started with gastrointestinal symptoms (nausea, vomiting, abdominal pain, and abdominal distension) and, later on, other classical features of SS were added.

SSRIs, including sertraline, can cause voiding dysfunctions ${ }^{[4]}$ However, these observations are silent regarding the presence of physical findings required for SS. Case 2 was on multiple serotonergic drugs. Each of these drugs may cause SS independently. Nausea, vomiting, and abdominal pain are reported in a few cases with SS. However, features suggestive of intestinal obstruction have not been reported previously.

Management of the SS comprises the removal of the offending drugs, providing supportive care, and the administration of 5-HT2a antagonists, especially cyproheptadine. ${ }^{[1]}$ Urinary symptoms (Case 1) and gastrointestinal symptoms (Case 2) improved in parallel with the improvement of other features of SS with cyproheptadine. Therefore, we speculate that urinary symptoms and gastrointestinal symptoms were the part of SS.

There is just one case report where urinary retention was one of the accompanying features of SS. ${ }^{[3]}$ However, to the best of our literature search, urinary retention as a presenting feature have not been reported. In the same way, nausea, vomiting, and abdominal pain are reported in a few cases with SS. However, features suggestive of intestinal obstruction have not been reported previously with SS.

\section{Pathophysiology}

Serotonin toxicity results from an increase in the intrasynaptic concentration of serotonin (5-HT), especially in the brainstem and spinal cord. In parallel to central 5-HT effects, peripheral 5-HT receptors 
and other neurotransmitters also contribute to the pathophysiology of SS. ${ }^{[1]}$ The different symptoms of SS are related to type of receptors or neurotransmitters involved.

Serotonin is an important neurotransmitter involved in the voiding functions. 5-HT2 receptors are located in Onuf's nucleus and control micturition reflex and urinary continence. ${ }^{[5]}$ In fact, in a study on rats, Duloxetine (norepinephrine and 5-HT reuptake inhibitor) prevented stress-induced incontinence by facilitating noradrenergic and serotoninergic systems. ${ }^{[5]}$ Therefore, our Case 1 was in accordance with the known physiology of serotonin receptors and drugs acting on these receptors, and urinary problems were the part SS symptom complex.

Serotonin is closely related to gastrointestinal motility and peristaltic reflex. Moreover, depending on various factors, it is related with both reduced gastrointestinal motility (constipation) and increased motility (diarrhea). ${ }^{[6]}$ SS usually causes diarrhea, but it may cause constipation. ${ }^{[1,3]}$ Case 2 was receiving combination therapy (paroxetine, tramadol, and ondansetron). Each of these drugs affects gastrointestinal motility. Therefore, multiple mechanisms could be speculated here.

\section{Conclusion}

SS is a highly underdiagnosed condition. This is partly due to unawareness by a physician of SS and partly because of its protean manifestation. Any patient who is on any serotonergic agent if develops a new symptom, should be suspected for the presence of SS.

\section{Financial support and sponsorship}

Nil.

\section{Conflicts of interest}

There are no conflicts of interest.

\section{References}

1. Boyer EW, Shannon M. The serotonin syndrome. N Engl J Med 2005;352:1112-20.

2. Prakash S, Patel V, Kakked S, Patel I, Yadav R. Mild serotonin syndrome: A report of 12 cases. Ann Indian Acad Neurol 2015;18:226-30.

3. Radomski JW, Dursun SM, Reveley MA, Kutcher SP. An exploratory approach to the serotonin syndrome: An update of clinical phenomenology and revised diagnostic criteria. Med Hypotheses 2000;55:218-24.

4. Lowenstein L, Mueller ER, Sharma S, FitzGerald MP. Urinary hesitancy and retention during treatment with sertraline. Int Urogynecol J Pelvic Floor Dysfunct 2007;18:827-9.

5. Miyazato M, Kaiho Y, Kamo I, Chancellor MB, Sugaya K, de Groat WC, et al. Effect of duloxetine, a norepinephrine and serotonin reuptake inhibitor, on sneeze-induced urethral continence reflex in rats. Am J Physiol Renal Physiol 2008;295:F264-71.

6. Sikander A, Rana SV, Prasad KK. Role of serotonin in gastrointestinal motility and irritable bowel syndrome. Clin Chim Acta 2009;403:47-55. 